\title{
Sacred Buildings and Brain Performance: The Effect of Sultan Hasan Mosque on Brain Waves of its Users
}

\author{
Sally Essawy, Basil Kamel, Mohamed Samir
}

\begin{abstract}
A sacred building is defined as a comfortable place that holds certain qualities similar to those originated from nature in harmony with its surroundings. The sacredness quality, though, usually pertains to Religious Buildings that allow for human comfort and a unique state of mind.

This paper investigates the effect of sacred buildings on human brain. It concentrates on measurements of brain waves during the presence of the user at certain Paths (coordinates) in these buildings. The variation and intensity of these measurements indicate the effect of "sacredness" as a quality on the user along his/ her journey through the building. This could be used in architecture as evidence of the presence of the sacred quality; and to study the intensity of the positive effect of these buildings. This process is based on a scientific experiment to determine whether or not buildings affect the brain wave frequencies of users, and, measures these effects in terms of Brain Wave Frequency Charts through EEG Devices.
\end{abstract}

Keywords: Sacred Buildings; Timeless Buildings; Brain Waves; Energy Lines; Power Spots; Sacredness.

\section{INTRODUCTION}

There is a certain quality, considered to be the root criterion of life and spirit in a living creature, town, building or space (Alexander, 1979). This quality is believed to be subtle, yet is capable of making a building divine. In essence, it is more than once summarized by a sense of "sacredness". Although many architects, theorists and critics attempted to reach a solid definition or even an objective one for this desired quality, yet most were only able to identify patterns, criteria and attributes that indicate the presence of this quality in a building or a certain space (Berkeley, 2002).

It's essential to define the meaning of the word "sacred" as applicable to architecture. Sacred architecture is usually defined as a building or monument that has a religious function, or uses the vocabulary of forms consistent with religious practices (Christopher, 2002).

Architecture is considered sacred when it has a common tie to the core basics of the quality of life, its soul and its spiritual vision, rather than merely becoming a form of religious representations. The spiritual

Creative Space

Vol. 1, No. 2

January 2014

pp. $125-143$

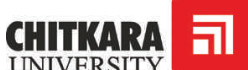

UNIVERSITY

C2014 by Chitkara

University. All Rights

Reserved. 
Essawy, S.

Kamel, B.

Samir, M.

sense is the active, dynamic aspect of the 'psyche', which is independent of forms. Those forms, into which spiritual energy flows, reflect a sense of the divine model that gives the buildings this sacred sense. Further, these buildings are set with such geometry that would allow for the adequate flow of this spiritual energy. This is why, and through history, sacred buildings were always associated with a strict system of geometrical measurements, proportions, and relationships, which communicate and transfer these sacred energies (Macchia, 2008).

\section{LITERATURE REVIEW}

Several architects and authors have discussed and developed the fundamental characteristics associated with this desired divine quality of space in their respective works (Hart, 2005). Some have attributed this quality to spiritual meaning while others focus on cosmic experiences. Similar descriptions include being organic, alive, whole, comfortable, free, egoless, exact and mostly "eternal". This led many of them to tag these feelings of eternity with the term "timeless quality", hence associating it with "timeless architecture" Christopher Alexander (1979), states that "there is one timeless way of building ... it is thousands of years old [yet] ... it is the same today as it has always been".

The earliest known explorations on the principles and guidelines for town planning and architectural design can be attributed to Marcus Vitruvius Pollio (The Ten Books on Architecture) in the First Century BCE, followed by the Italian architect, Andrea Palladio (The Four Books on Architecture) in 1570. The explorations associate proportions and geometry with qualities and feelings both on the scale of the building components and the building's setting in its surrounding. Of course, the relations and associations could be read as subjective as they were not supported by experimental confirmations.

In 1977, Christopher Alexander (et al), authored "A Pattern Language: Towns, Buildings, and Construction", an exploration on patterns applied to varying scales of the built environment. The work was deduced from intense observations that associate forms and geometrical physical representations with behavior and use on the one hand, and feelings, emotions and the sense of belonging on the other.

In continuation to these efforts, this paper attempts to verify the effect of these "timeless buildings" on human brain and, hence, human emotions. Through comparative experiments, several measurements were taken of Alpha and Theta brain waves in an attempt to identify its effect, following steps 
of measuring stress levels in terms of brain waves in evaluation studies of meditation places (Ospina, 2007).

\section{THE DOMAIN OF THE SACRED}

To begin with, it is essential to understand where sacred sites are located, as this is one of the basic principles of sacred architecture.

When we speak of sacred architecture we are not speaking just of churches, mosques and temples, but of all buildings that are designed in accordance with the laws of sacred geometry (Garg, 2010). Sacred geometry, unlike the Euclidian geometry we learnt in school, is primarily concerned with the esoteric and symbolic significance of geometrical forms, rather than their logical development and application. When the principles of sacred geometry are understood and correctly applied in the design and construction of buildings, those buildings will possess a "magical" power that can speak to the deeper layers of our awareness. These Sacred Buildings are considered to have great effect on human beings on both the physical and psychological levels, as they are considered harmonized built environment to live in (Karim D. I., 2010). Few buildings designed in our time possess this power and deserve to be called classified as "sacred" (Bangs, 2006).

\section{THE SULTAN HASSAN MOSQUE OF CAIRO}

The Sultan Hassan Mosque was built in Cairo in 1361 A.D., and is probably the most famous building from the Mamluk Era. (Fig. 1) The building housed the first madrasa ${ }^{1}$ in Cairo and was referred to by many historians and architects as the finest ancient Cairene mosque. It has been praised as one of the major monuments of the Islamic world (Kareem, 2002).

The mosque of Sultan Hassan was a madrasa for the four rites of Islamic law. For the first time in Cairo, the madrasa had also the status of a congregational mosque for the Friday sermon ${ }^{2}$. The building consists of a square central courtyard with four great $\operatorname{Iwans}^{3}$ (Fig. 2). The largest of the Iwans is a prayer hall behind which is the domed mausoleum of Sultan Hassan (Fig. 3). Between the four Iwans are four separate courtyards, one for each of the orthodox Sunni rites of Islamic law. The foundation was ambitious in

1 School

2 On Fridays, Muslims should gather to pray together for the noon prayer in large mosques, rather than individually at home.

3 Iwan (also termed Liwan occasionally) is a rectangular hall, usually vaulted, walled on three sides, with one end entirely open, while the opposite has the mehrab for indicating the direction of prayer.
Sacred Buildings and Brain

Performance the Effect of Sultan

Hasan Mosque on

Brain Waves of its Users

\footnotetext{
$\longrightarrow$
} 
Essawy, S.

Kamel, B.

Samir, M.

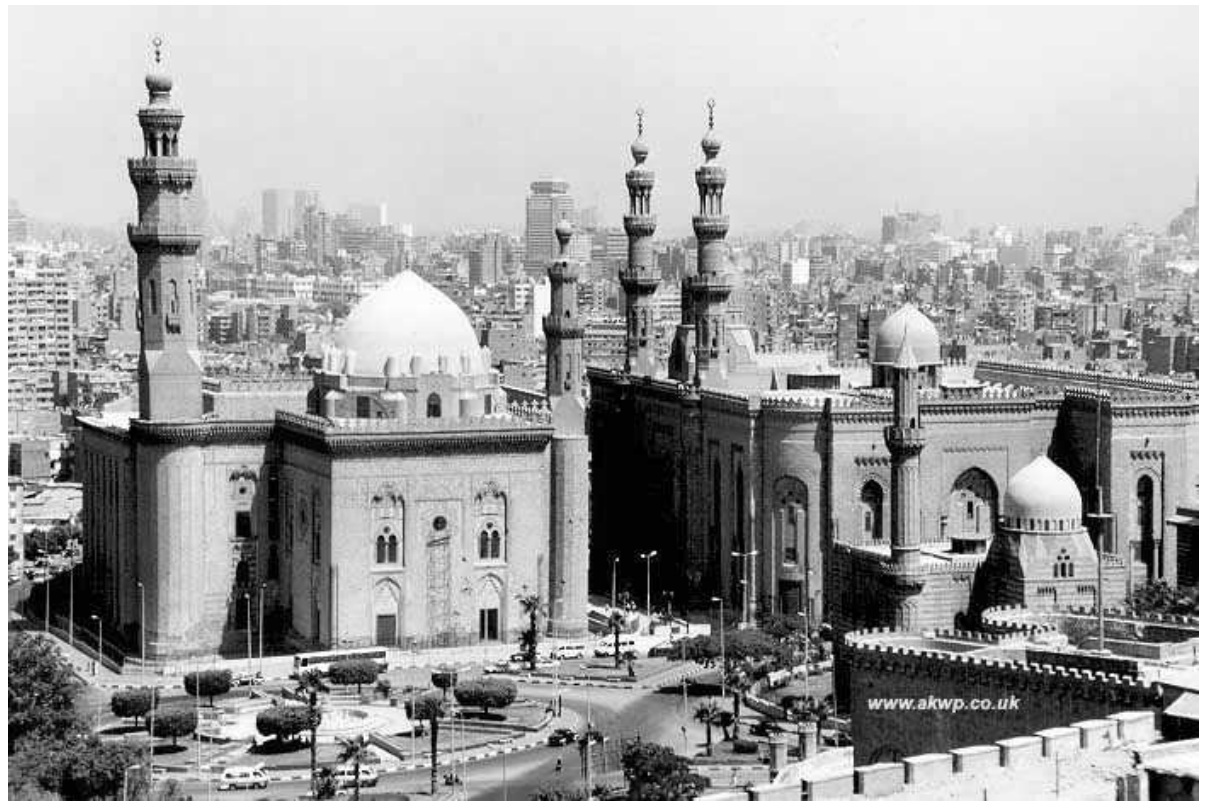

Figure 1: A view of the Sultan Hassan Mosque from the nearby citadel. (Image Source: http://www.beautifulmosque.com/mosque-madrassa-of-sultan-hassan-cairo-egypt/)

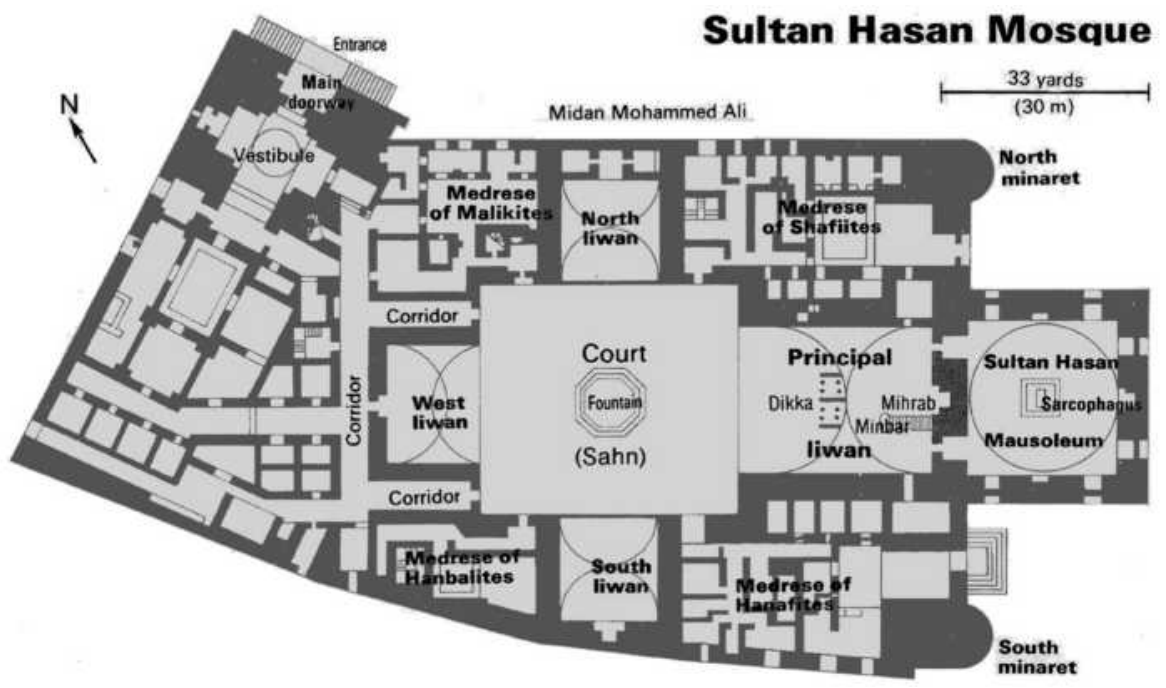

Figure 2: Plan of the Sultan Hassan Mosque (Adapted from @ planetware.com) 


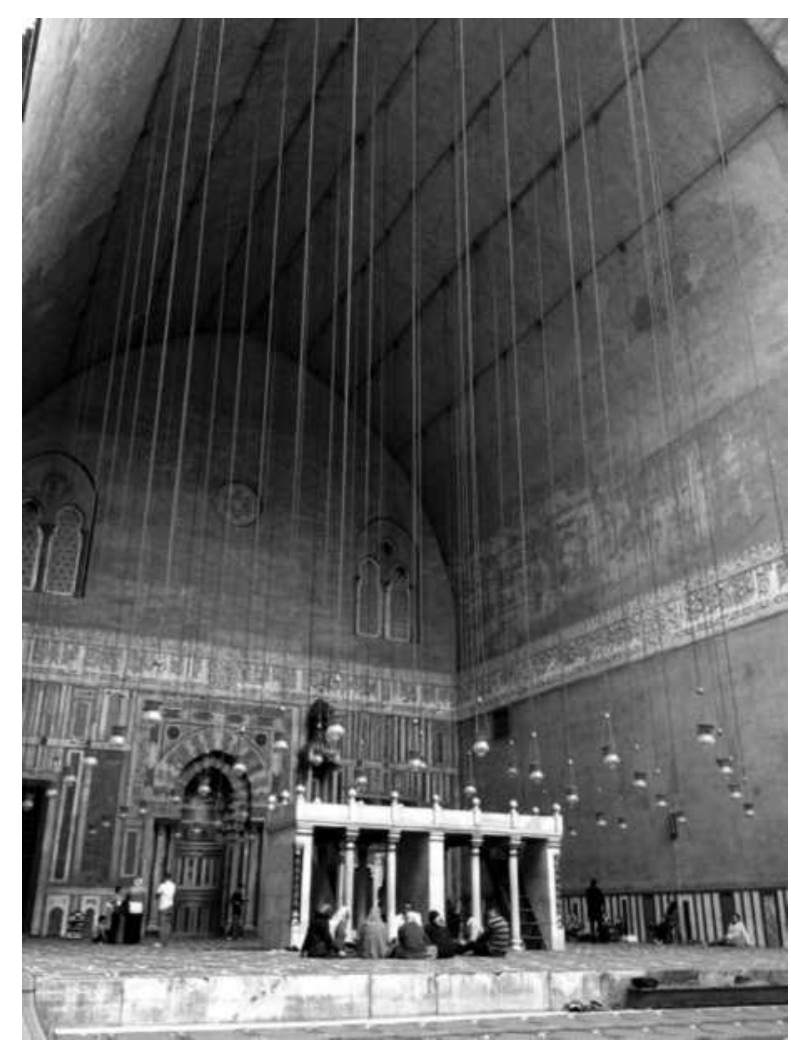

Figure 3: The largest and the main Iwan of Sulatn Hassan Mosque (Image Source: Sally Essawy)

every respect. In terms of architectural proportions, it is the most gigantic of Cairo's mosques, built to house four hundred students. The building includes several notable architectural features, amongst which are the doorway thought to be modeled on that of the Gök Madrassa at Sivas, and the floriated stucco inscriptions in the prayer hall (Petersen, 2002).

The center of each of the three mausoleum facades is decorated with a medallion with a bull's-eye in the center, framed by interlaced bands in two colours. Also, there are two rows of windows, the upper ones inserted in recesses crowned with stalactites surmounted by a shallow conch, an arrangement similar to portal treatments (Herz, 1899). The height of this arrangement and its simplicity give this façade a strangely modern appearance. The portal occupies the whole length of the facade, making it by far the largest in Cairo. Its most remarkable feature is that it is set at an angle to the rest of the façade so that it can be seen when approaching along the street. A cascade of dripping stalactite forms, surmounted by a fluted half-dome dominates the portal (Rogers, 1971) (Fig. 4). 
Essawy, S.

Kamel, B.

Samir, M.

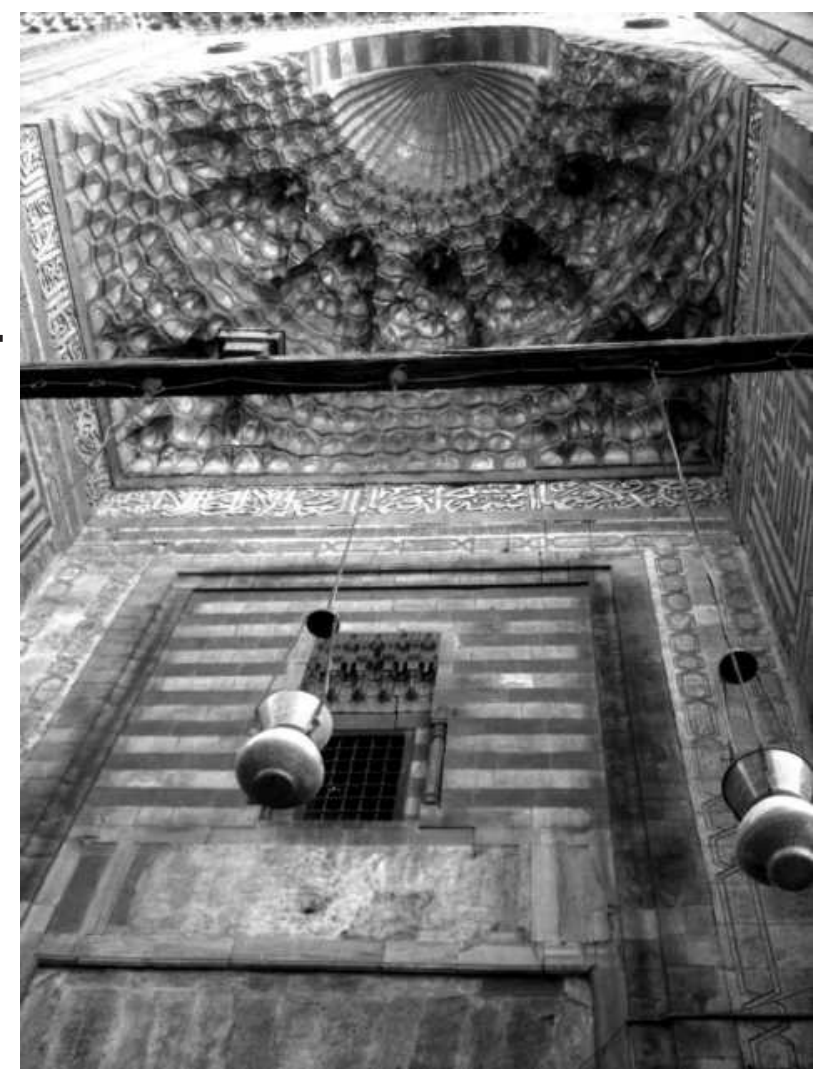

Figure 4: The cascade of dripping stalactites of the main portal (Image Source: Sally Essawy)

The Iwan of Sultan Hassan is richly decorated. The kiblah ${ }^{4}$ wall is paneled with a large polychrome marble dado, as is the prayer niche, flanked with columns whose style indicates that they must be trophies from Crusader buildings in Palestine (Fig. 5). A marble dikkat al-muballigh ${ }^{5}$, the bench standing in the sanctuary near the courtyard, is adorned with remarkable columns composed of different colored stones (Fig. 6). It is topped by a carved bulb and has a portal leading to the steps with stalactite cresting. A beautiful bronze door with openwork dominates in a unique technique. The most remarkable feature of the kiblah Iwan is the large inscription band that runs along its three walls, made of stucco with ornate Kufic script on a background of lotus blossoms (Doris, 1989).

4 Direction of Mecca, towards which Muslims must face during their prayers

5 The reading bench standing in the sanctuary that represents the pulpit for the Friday sermon 


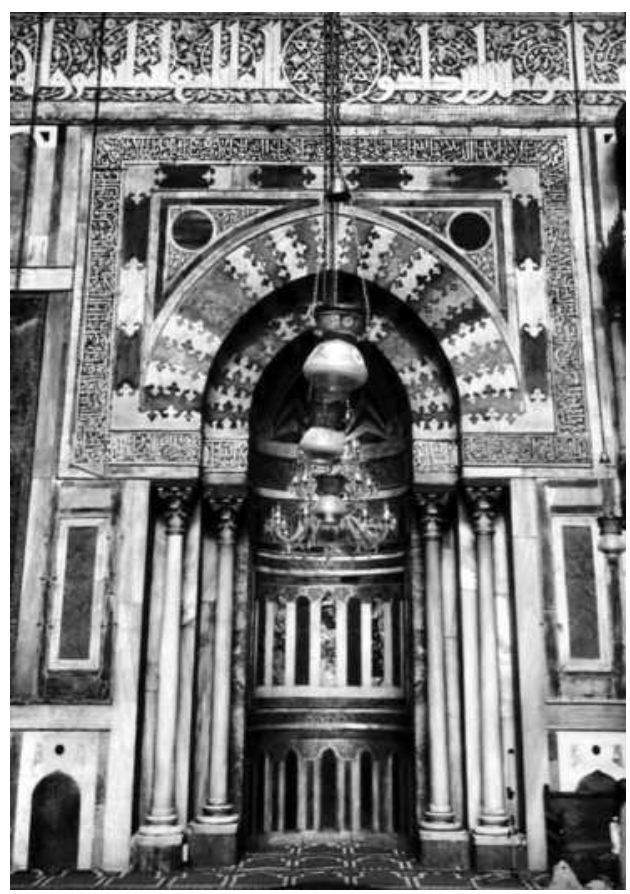

Figure 5 (Left): The prayer niche in the Kiblah wall (Image Source: Sally Essawy)

Figure 6 (Below): "Dikkat al-muballigh" with its remarkable columns (Image Source: Sally Essawy)

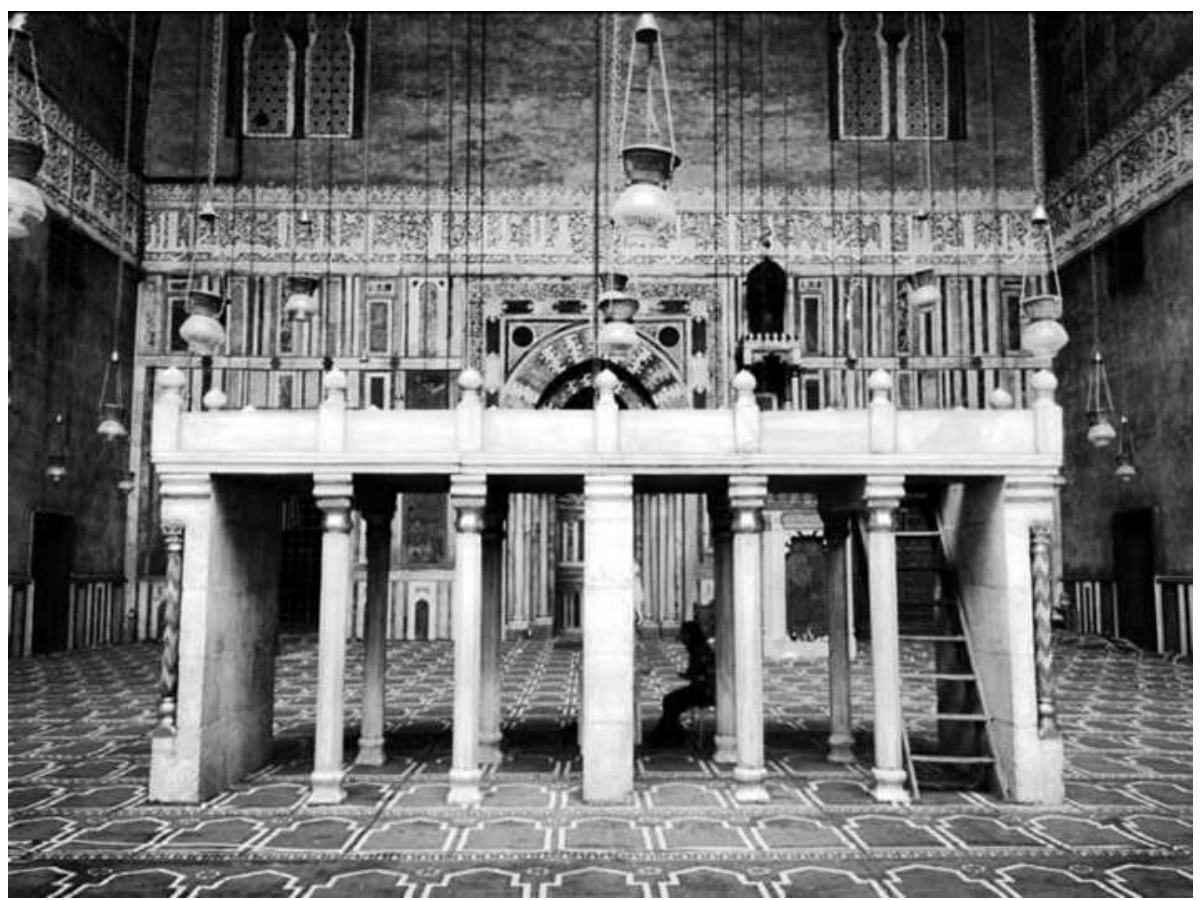


Essawy, S.

Kamel, B.

Samir, M.

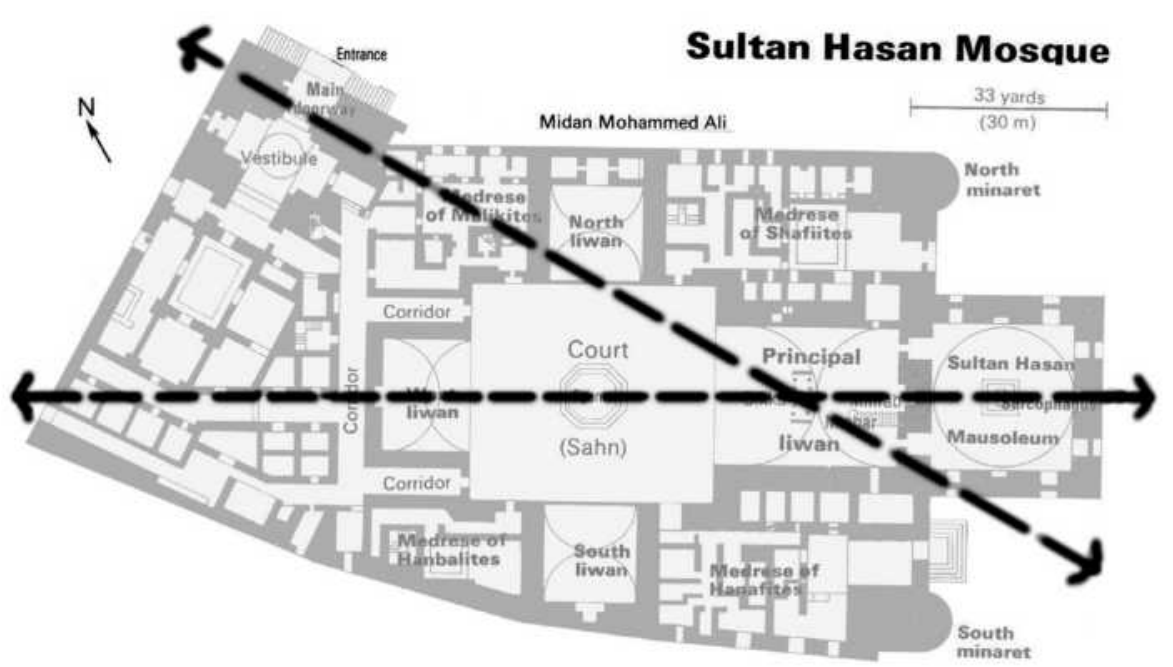

Figure 7: Intersection of two major energy grid lines in Sultan Hassan mosque (Based on original lines application by Karim I 2010; Karim D. I., 2010)

\section{Sacred Quality}

The building is also considered a good example of the survival of the sacred knowledge in recent history, as the layout of the building followed, in its grid patterns, a change in direction according to the earth energy. This gives an adaptation to energy grid lines that indicate sacred paths, which accordingly provide the building with sacredness quality. The energies of these paths (strongest at the intersection of energy grid lines) interact with the body's energies, connecting the users with the transcendental center of their being (Karim D. I., 2010). By applying the grid lines on the Sultan Hassan plan, it was found that the intersection of the two grid lines are perfectly matched with the spot where the leader of prayer (Emam) stands during the prayers, behind main $M i h r a b^{6}$. Furthermore, one of them extends to reach the sacred tomb of Sultan Hassan in perfect alignment along its axis of symmetry, while the other grid line passes also through the axis of the main entrance (Fig. 7). The building stands as a representative of a unique architecture and spatial experience. The sacredness of the building is an expression of its space organization, sense of grandiose, attention to details and respect to the user as well as a feel of healing and spiritual uplift.

6 A niche in every Iwan in the mosque that is pointing towards Mecca. 


\section{THE SACRED BUILT ENVIRONMENT AND HEALTH (THE BIO- PSYCHOSOCIAL MODEL OF HEALTH)}

Does the built environment contribute to health? To contemplate this, one must ask what it means to be healthy. The World Health Organization (WHO), health-care professionals, and the general public today, equates good health not merely to the absence of disease, but also to the presence of positive well-being (Brannon, 2002). In 1987, George Stone classified the available definitions of health into two broad categories: 1) Health as an ideal (static) state of positive well-being and, 2) Health as a (dynamic) state of consistently moving towards positive well being. "The traditional model of health has therefore, given way to the bio-psychosocial model -- a model that advocates a greater holistic approach towards health, considering not only our biological, but also our social, psychological, physiological, as well as our spiritual health" (Rodrigues, 2008).

\section{Specific Health Issues associated with Spirituality}

Although spirituality is acknowledged as a healing adjunct among various cultures since ancient times, only recently were scientists able to quantify specific and related health benefits. Several studies have shown that spirituality is associated with better health results for human beings, coping skills and health-related quality of life, as well as with lower rates of anxiety, depression and suicide (Rodrigues, 2008).

Along these lines, further studies have confirmed that spirituality is positively associated with quality of life, and negatively correlated with despair, hopelessness, anxious mindedness and relatively cognitive disorder (Ospina MB, 2007), and that this does not relate to a certain religion's rituals in any of these references.

\section{SACRED BUILDINGS AND STRESS-LESS QUALITY OF LIFE}

Christopher Alexander described timeless quality as "Places, which are comfortable because they have no inner contradictions, because there is no little restlessness disturbing them" (Alexander,1979). He also stated, "There are kinds of comfort which stultify and deaden too. It is too easy to use the word for situations, which have no life in them because they are too sheltered (Alexander, 2003). Thus, inside the sacred buildings he, as well as other theorists, describes that experience as timeless where one feels at ease, in harmony with oneself and stress-less. This paper makes a scientific attempt to put scientific evidence and definition of this state of mind and body in terms of Tangible Brain Waves effect.
Sacred Buildings and Brain

Performance the Effect of Sultan

Hasan Mosque on Brain Waves of its Users

.


Essawy, S.

Kamel, B.

Samir, M.

\section{Alpha Brain Waves}

Alpha brain waves occur when one is conscious and alert, yet in a state of relaxation and calmness. In this state, one is more easily able to access creative ideas. According to therapist and meditation expert Patt Lind-Kyle in her book, "Heal Your Mind, Rewire Your Brain: Applying the Exciting New Science of Brain Synchrony for Creativity, Peace and Presence," your right brain is most active when Alpha Waves are emitted and your left brain is most active when Beta Waves are produced. When the two hemispheres of your brain are synchronized, you are able to operate in a state of calm awareness. Alpha Brain Waves promote feelings of contemplation, peace, relaxation and stillness.

\section{Theta Brain Waves}

Theta Brain Waves occur between 4 and $7 \mathrm{~Hz}$. The only state slower than this is the state of Delta Brain Waves -- which is the state of deep, dreamless sleep (even Zen Masters find it hard to stay conscious at these levels). When human brain is producing Theta Brain Waves, one will feel deeply, deeply relaxed. Yet, Dr. Thomas Budzynski, one of the world's foremost authorities on biofeedback, noted that Theta Brain Waves produce "a sensation of detached relaxation" with "results ranging from... drowsy, (hypnotic) like states, to vivid, holograph-like images" (Budzynski, 2012). Such a state of mind is related to higher creativity and, what is called a super learning state. An increase in Theta State creates a sense of Balance, Calmness, and contributes to better Health.

\section{AN INVESTIGATION OF THE RELIABILITY AND VALIDITY OF THETA/BETA RATIO MEASUREMENT}

The ratio between power in different frequency bands has been used to evaluate changes in the EEG that occur due to normal maturation (Matousek and Petersen, 1973) and as a measure of cortical arousal, which are both theoretically pertinent to hyperactivity disorder syndromes (Lubar, 1991). In 1984 Matousek et al. investigated to find that the theta/alpha ratio was a good predictor of group differences between children with MBD, ADD and control subjects (Matousek and Petersen, 1973).

Theta/beta ratios were also calculated for 25 hyperactive and 27 control subjects during a drawing task. The hyperactive subjects had a greater ratio at all sites compared to the control subjects, with the greatest difference in the frontal electrode sites. Janzen also reported that children with hypertension and activity had a higher theta/beta ratio than control subjects (Janzen et al, 1995). This was considered to reflect a reduction in alpha activity resulting from a localized deficit 
in cortico-cortical or thalamo-cortical systems. Delayed maturation in the alpha rhythm circuits was seen as the most plausible explanation. Clarke and others found that both the theta/alpha and theta/beta ratios can differentiate between groups of normal subjects and subjects with hyper tension (Clarke et al, 2001). Bresnahan adult studies have confirmed that the theta/beta ratio remains elevated in $\mathrm{AD} / \mathrm{HD}$ from children to adults (Bresnahan and Barry, 2002). Further, the ratio distinguished adults who met hypertension disorder criteria from those with some symptoms of the disorder who failed to meet those criteria, indicating some specificity for this marker in behavioral disorder and hypertension (Bresnahan, 1999). In general, anomalies appear to be more pronounced in subjects with $\mathrm{AD} / \mathrm{HD}$ combined type than $\mathrm{AD} / \mathrm{HD}$ inattentive type. Both the theta/alpha and theta/beta ratios also appear to be reliable measures differentiating between subjects with hyper tension and control subjects, as well as between different types of disorder, with neither measure demonstrating greater sensitivity than the other, although the theta/beta ratio is preferred by some researchers (Lubar, 1991).

Thus we can conclude that the higher is the theta/beta ratio, the more tensed and hyper active is the brain; the lower is the theta/beta ratio the more relaxed and aware is the brain; and the higher is the alpha brainwave the more is the relaxation level.

\section{Electroencephalogram (E.E.G.)}

The combination of millions of neurons sending signals at the same time produces an enormous amount of electrical activity in the brain. This electrical activity can be detected using sensitive medical equipment and allows for measuring electricity levels over areas of the scalp. The combination of electrical activity of the brain is commonly called a brainwave pattern, because of its cyclic, wavelike nature. Electric waves can be registered by an Electroencephalogram; a device connected via several types of connections to brain cells by certain sensors that can transfer its waves to the computer. There are several types and categories of this device; some are huge, fixed in hospitals, and others are quite small and even portable (such as Enobio wireless brain monitoring and Somno Watch plus wave recorder). The Pro-Comp 5 EEG portable device via BIOGRAPH software was used in the experiment due to its portability and ease of use in different sites.

\section{THE EXPERIMENT}

At this stage of the research, the experiment aims to measure the change in brain wave readings inside timeless buildings for users subjected to the study.
Sacred Buildings and Brain

Performance the Effect of Sultan

Hasan Mosque on

Brain Waves of its Users

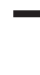


Essawy, S.

Kamel, B.

Samir, M.

As is known in health care, Meditation is used in relieving a person from stress and pain, is known for reducing heart rate and blood pressure of a person (Kabat-Zinn \& Lipworth, 1985), and is practiced as a brief and practical selfhelp stress management strategy. It also helps in the regulation of metabolism by lowering the biochemical byproducts of stress (Vijayalakshmi. K, 2010).

In this research we aim to reach the same relaxed awareness effect by the subject's presence in a timeless building as an effect of the quality of these buildings. This could be reached by a decrease in theta/beta ratio, which indicates the relaxation or state of decreased tension and stress, and also increase in alpha wave that indicates state of relaxation accompanied harmonious connectedness (Ogrim et al, 2012). This experiment is applied with reference to a similar experiment, investigating Analysis of Neuro Cognitive Effects on Meditation in a certain building designed to provide an access to the mental states beyond normal consciousness. It is an attempt to score the meditation course by studying the variation in EEG parameters (Lehmann et al, 1998).

\section{Sampling}

The Sampling of the experiment is derived from two parallel branches:

A: The Selected Building: Sultan Hassan Mosque, which is representative of the analysis of paths aligned with energy grid lines, stated in the earlier stage of this paper so as to represent qualities of sacred buildings.

B: Population: Purposive Sample of male/female users, were subjected to the same time frame of exposure to the building under study at the same selected paths. All users subjected to the experiment were of normal health level and had the same vital results from their general tests, i.e., normal blood pressure, no diabetes, no evidence of any disease history or malfunction of organs.

\section{Data Acquisition System}

Recording was carried out using Pro-Comp 5 EEG portable device ${ }^{7}$ with a 4-channel Data acquisition system, A/D conversion of 24 bits, sampling frequency of $256 \mathrm{~Hz}$, inbuilt filter setting options and self-calibration mechanism. The data acquisition system can be connected to a personal Computer via USB. The SS2L electrodes and transducers, which receive the signals, employ sensors that allow the software to communicate with the

7 Pro-Comp 5 medical devices for diagnostics and Therapy 


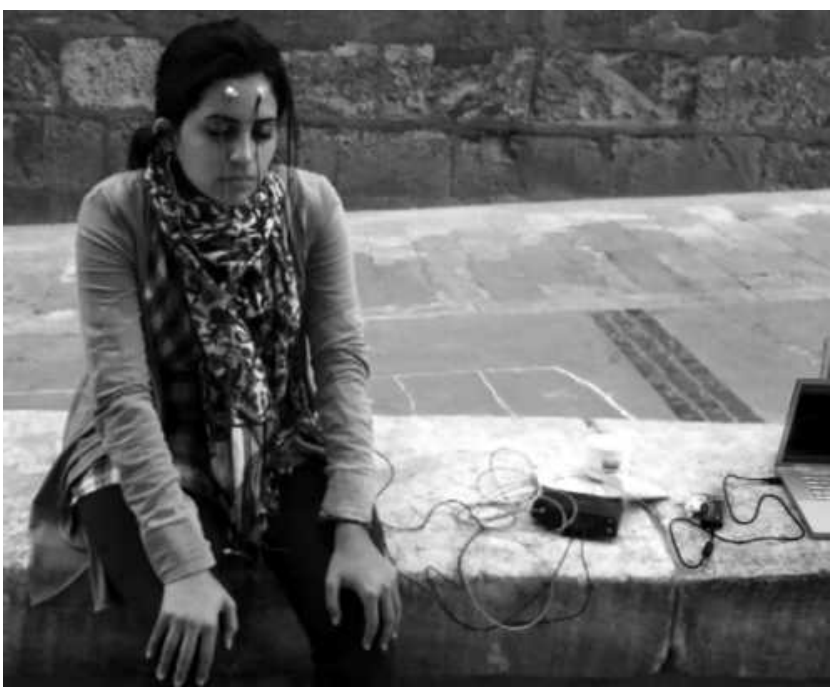

Sacred Buildings and Brain

Performance the Effect of Sultan

Hasan Mosque on

Brain Waves of its Users
Figure 8: BioGraph EEG Data Acquisition System as hardware is connecting subjects to computer (Image Source: Photograph by Sally Essawy on the experiment location)

subjects. SS2L leads having electrodes were connected to channel 1 of ProComp 5 EEG portable device via BIOGRAPH software.

\section{EEG Electrode Placement}

Three electrodes were placed on the subject's scalp. The first electrode was placed on the ear lobe (ground), second on the occipital lobe (negative) and the third on the parietal lobe (positive) (Fig. 8)

\section{Recording System Setup and Methods}

Fifteen subjects were considered from the age group between 19-35, both male and female. The setup consisted of a PC, using 24 bits A/D converter, Pro-Comp 5 EEG portable device, and suitable disposable pre-gelled EEG electrodes. Subjects were instructed to stay in certain paths (near the intersection point of grid lines) previously marked inside the building for thirty minutes, after which the EEG is recorded using BIOGRAPH software.

During the recording process subjects were asked to relax with their eyes closed and the readings were taken for 10 minutes. The electrodes were secured to their positions using a good conductor gel. The surrounding area was kept quite to help the subject relax mentally. First the calibration procedure was carried out to establish the hardware's internal parameters such as gain, offset and scaling. Calibration is critical for optical performance. Then the recording of the EEG signal was carried out. This procedure was repeated for each of the subjects, both before and after the experience inside the selected building. 
Essawy, S.

Kamel, B.

Samir, M.

\section{Procedure}

STEP 1 Each subject in the population is subjected to blood pressure measurements before entering the building and connected to the EEG device.

STEP 2 Measuring brain waves via EEG connections outside the building before going inside, using the Pro-Comp 5 EEG portable device via BIOGRAPH software.

STEP 3 Each subject then stays inside the building (at pre-set spots that are proved in previous studies to represent intersection points of earth grid lines) and keeps his/her position for 30 minutes (suitable time taken for brain wave change to settle according to Analysis of Neuro Cognitive Effects) (Vijayalakshmi.K, 2011)

STEP 4 Measuring brain waves again via same EEG connections after the 30 minutes period passes. (Fig. 9, 10, 11) .

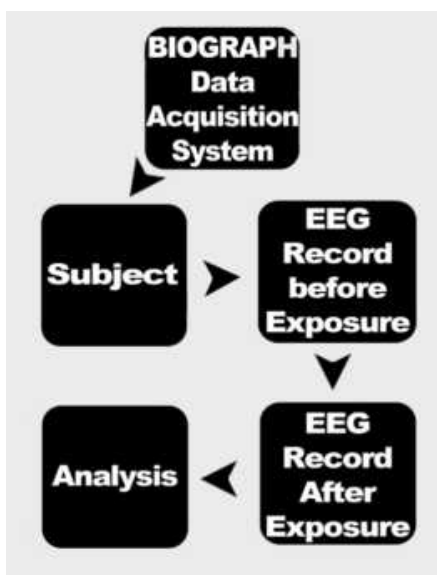

Figure 9: The experiment steps of measurements

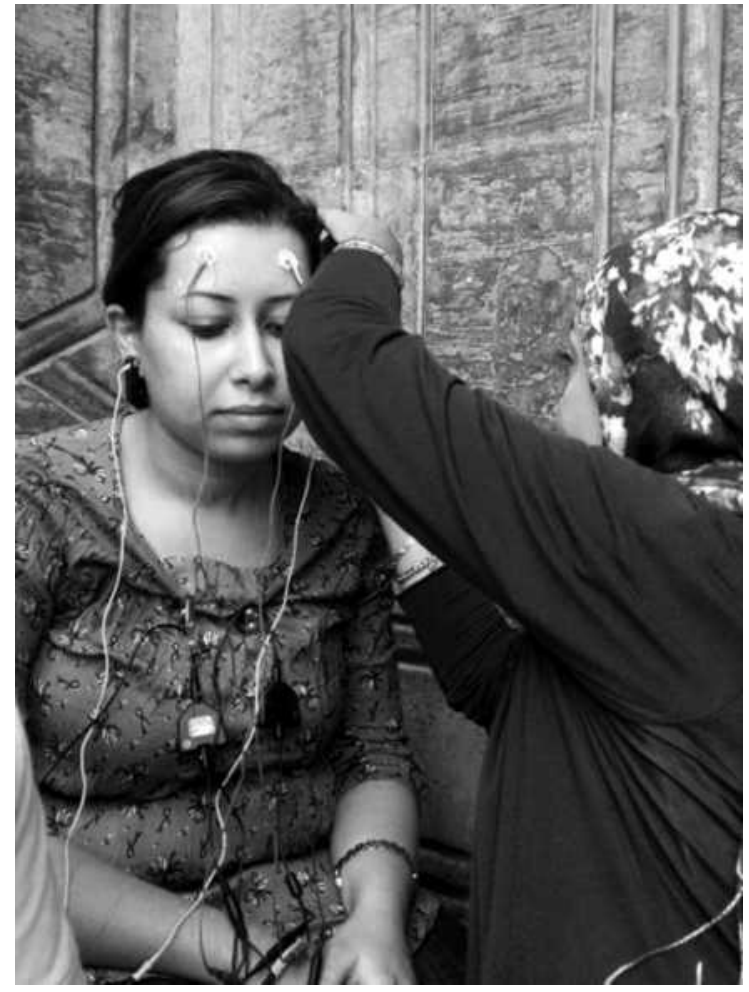

Figure 10: The process of placing electrodes on specific centers on the subjects' forehead and ear lobes (Image Source: Sally Essawy) 


\section{Statistical Analysis}

Statistical analysis is carried out in Time domain, using BGI BioGraph Infinity software. Four parameters were mainly studied; Theta/Beta ratio, Alpha/Theta ratio, Alpha mean and Alpha peak frequency. The rest of the brain chart was also derived from the software connected to the measuring device for further investigation and Standard deviation was also studied. (Fig. 12)

\section{Results}

Participants who spent 20 minutes in the mosque experienced a different brain wave vibration rate and integration than what was recorded for them before entering the building. Thus we can conclude that this mosque has a physical and psychological effect on its users.

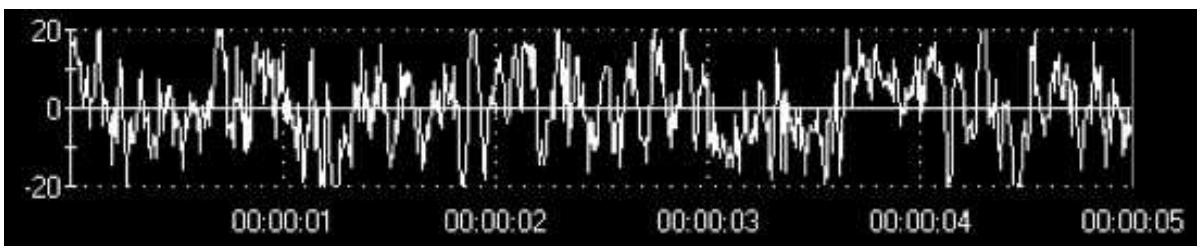

Figure 11: EEG Brain waves recorded before and after 30 minutes of entering the building (Biograph software screens)
Sacred Buildings and Brain

Performance the Effect of Sultan

Hasan Mosque on

Brain Waves of its Users

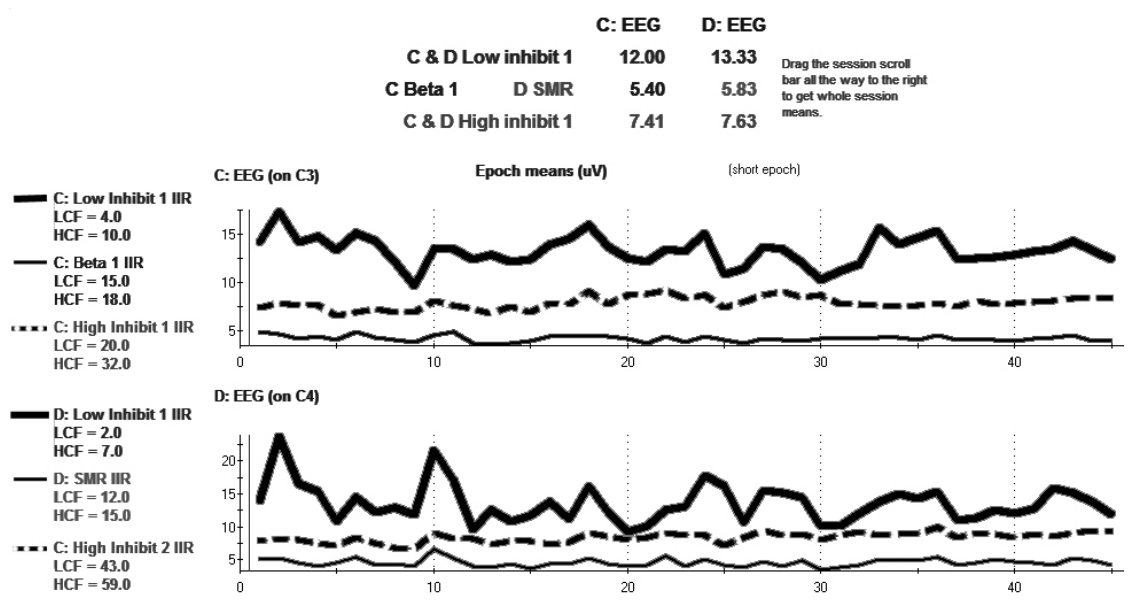

Figure 12: The graph recorded after 30 minutes of being subjected to the building experience (Biograph software screens) 
Essawy, S.

Kamel, B.

Samir, M.

\begin{tabular}{|c|c|c|c|c|c|c|c|c|c|c|c|}
\hline DATE & s! & 52 & 53 & $s$ & & & s7 & 5 & s9 & & \\
\hline BEFORE & $10 \%$ & 90 & 80 & 80 & 90 & 80 & 90 & 90 & 80 & 100 & 100 \\
\hline AFTER & 90 & 100 & 90 & 90 & 80 & 120 & 100 & 80 & 120 & 100 & 110 \\
\hline
\end{tabular}

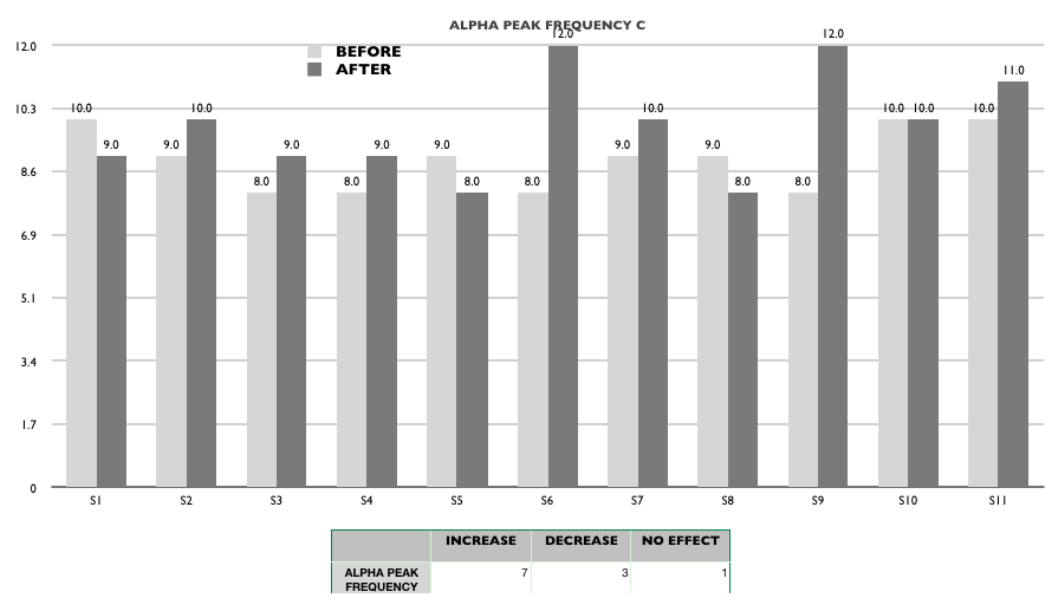

Figure 13: Alpha Brain waves before and after exposure

As one of the most measurable effects in a short interval of time is human stress, which is reflected in brain wave frequencies, it is measured in this experiment (indicated in brain wave frequencies) using EEG device. The results are recorded and interpreted in the form of tables, graphs and diagrams to prove the effect of timeless buildings on stress release of users. (Fig. 13, 14)

\section{DISCUSSION}

Given the exploratory nature of this study, only one active EEG channel was employed and no adjustments were made for repeated tests. Even within this simple paradigm, interesting and suggestive results were found

In Sultan Hassan Mosque, strong negative correlations were evident between peak frequency and the theta/beta ratios in both conditions. The strength of the correlation increased between the two conditions respectively. This supports the hypothesis that subjects who displayed increased energy at higher frequencies would also display lower Theta to Beta ratios and that the difference would increase when subjects performed a difficult task requiring sustained concentration. 


\begin{tabular}{|c|c|c|c|c|c|c|c|c|c|c|c|}
\hline DATE & sI & S2 & S3 & 54 & S5 & S6 & S7 & S8 & s9 & $\$ 10$ & sII \\
\hline BEFORE & 1.9 & 1.7 & 1.8 & 2.1 & 1.3 & 3.4 & 1.5 & 1.1 & 1.2 & 1.8 & 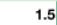 \\
\hline AFTER & 1.8 & 1.0 & 1.7 & 1.8 & 1.2 & 2.5 & 1.2 & 1.0 & 1.0 & 1.9 & 1.5 \\
\hline
\end{tabular}
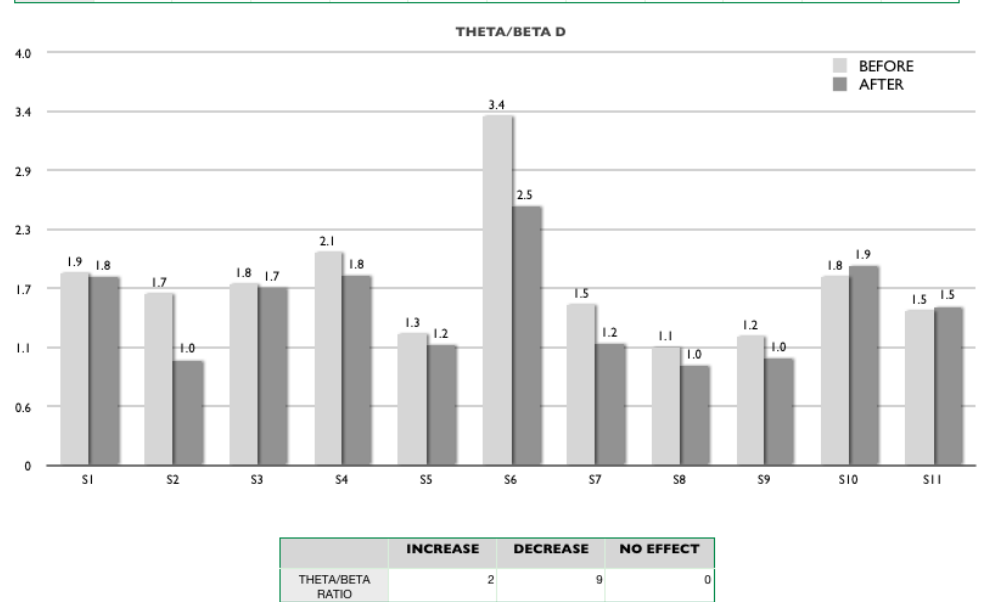

Figure 14: Theta/Beta Brain waves before and after exposure

However employed subjects displayed lower Theta to Beta ratios and higher Alpha peak frequency (healthier EEG). To determine the relationship between brain statuses of subjects using EEG, a test was calculated for the Theta to Beta ratios, Alpha peak, and peak frequency values. The same statistics were used for comparing those subjects' brain performance before and after being subjected to the selected buildings. The use of a Theta to Beta ratio was based on research by Lubar (Lubar,1991), which demonstrated that this ratio might be more appropriate than the use of independent percentages of Theta or Beta alone as it provides one overall figure to use for statistical comparisons.

\section{CONCLUDING REMARKS}

As the variation in mean and standard deviation of Alpha and Theta waves were measured and analyzed, one can conclude that the Mean Value of Alpha wave for nine of the subjects showed an increase whereas six subjects showed a decrease after being subjected to the building experience. That is $63.64 \%$ of the subjects showed an increase while $36.36 \%$ of the subjects showed a decrease in alpha activity. The amplitude of theta parameters for 8 of the
Sacred Buildings and Brain

Performance the Effect of Sultan

Hasan Mosque on Brain Waves of its Users 
Essawy, S.

Kamel, B.

Samir, M.

subjects showed an increase, which accounts for $72.7 \%$ while 3 of the subjects showed a decrease, which accounts for $27.3 \%$. Thus, increases in the Alpha and Theta parameters showed the suggestive of relaxation after staying for 30 minutes inside the building along the path of energy grid lines.

As has been proven, the effect through the use and experience of timeless buildings demonstrates this 'suggestive of relaxation'. The mental exercise of relaxation is especially beneficial for people with high blood pressure. Indulging in relaxed awareness helps the body fight against chronic diseases, like arthritis. Relaxed awareness lowers the risk of high cholesterol levels and cardiovascular diseases. It may also increase the lung capacity, if done on a regular basis.

Further studies need to be conducted to consider several variables that were omitted during the experiment; effect of crowd, noise levels, time of the day when experiment was conducted and others. Furthermore, more advanced equipment can be used. In this analysis a four-channel data acquisition system was used. For better analysis 16 channel data acquisition system with 10-20 electrode systems can be used. Larger numbers of subjects need to be studied to define these changes further.

\section{REFERENCES}

ALEXANDER, C. (1979) The Timeless Way of Building. New York: Oxford University Press.

BEHRENS-ABOUSEIF, D. (1989) Islamic Architecture In Cairo. Cairo: The American University in Cairo Press.

BRANNON, J. F. L. (2002) Health psychology: An introduction to behavior and health. Canada: Wadsworth/Thomson.

BUDZYNSKI, T. (2012) Theta-brain-waves. [Online] Available from: http://www. binauralbeatsgeek.com [Accessed: October 2012].

GARG, S. (2010) Coming Togethe, a Universal Sacred Space. Washington DC: UMI. (Masters Theses from the Corcoran College of Art + Design, Washington, D.C.)

GILMORE, R. L. (1994) American Electroencephalographic Society Guidelines in electroencephalography, evoked potentials, and polysomnography. Clinical Neurophysiology. 11(1). p. 147.

HERZ, M. (1899) La mosque du Sultan Hassan au Caire. Egypt: Comite de conservation des monuments de l'art arabe.

KABAT-ZINN, J. \& LIPWORTH, L. B. R. (1985) The clinical use of mindfulness meditation for the self-regulation of chronic pain. Journal of Behavioral Medicine. 8. p. 163-190. http://dx.doi.org/10.1007/BF00845519

KARIM, A. (2010) Sultan Hassan Mosque. Journal of Islamic Architecture. 1(2).

KARIM, I. (2001) The Egyptian Science of BioGeometry. Veranda architecture Magazine, May-June Issue.

KARIM, I. (2010) Back to a future for mankind. CreateSpace Independent Publishing Platform.

MACCHIA, P. (2008) Understanding the Sensual Aspects of Timeless Architecture. New York: Horizon Press. 
MATOUSEK, M. and PETERSEN, I. (1973) Frequency analysis of the EEG in normal children and normal adolescents. In KELLAWAY, P. and PETERSEN, I. (eds.). Automation of Clinical Electroencephalography. New York: Raven Press. p. 75-102.

MORGAN, H. M. (1914) Vitruvius. The Ten Books on Architecture. Cambridge: Harvard University Press. (Translated from the original De architectura by VITRUVIUS).

OGRIM, G. et al. (2012) The Quantitative EEG Theta/beta Ratio in ADHD Disorder and Normal Controls: Sensitivity, Specifity and Behavioral Correlation. Elsevier.Amsterdam.

PETERSEN, A. (2002) Dictionary Of Islamic Architecture. London: Taylor \& Francis.

RODRIGUES, A. T. (2008) The Sacred in Architecture: A Study of the Presence and Quality of Place-making Patterns in Sacred and Secular Buildings. Texas: A\&M University.

VIJAYALAKSHMI, K. (2010) Estimation of Effects of Alpha Music on EEG Parameters by Time and Frequency Domain Analysis. International Conference on Computer \& Communication Engineering. Malaysia.

WALY, T. (1996) Madrasa of Sultan Hassan. Cairo: Tarek Waly Center, Architecture and Heritage.
Sacred Buildings and Brain

Performance the Effect of Sultan

Hasan Mosque on Brain Waves of its Users 